\title{
Research on the Interactive Relationship Between Theme Park and Regional Economy----Taking the Economic Interaction Between Lehua City Resort and Xixian New District as an Example
}

\author{
Xi Lei \\ Xingzhi College of Xi'an Univerity of Finance and Economics, Xi'an Shaanxi Province 710038, \\ China.
}

Keywords: Theme Park, Regional Economy, Interaction, Lehua City Resort, Xixian New District.

\begin{abstract}
The theme park is a new tourism attraction bred by modern tourism in the development of tourism resources. It is a leisure vacation and tourism activity space that combines the marginal resources of natural resources and human resources, information resources and business activities of tourism companies. It is based on a specific theme, using modern science and technology and multilevel space activities, a variety of entertainment content, leisure elements and service reception facilities in one modern tourist destination. This article mainly introduces the economic interaction between Lehua City Resort and Xixian New District, as well as their mutual influence and promotion.
\end{abstract}

\section{Introduction}

Large-scale theme parks have unique cultural connotations, technological content, and powerful entertainment features that continue to attract more and more popular tourists. Although the nature and extent of the theme park's impact on urban economic development and regional tourism competition are still unknown, large-scale theme parks have increasingly become engines and boosters for urban economic restructuring and regional tourism development. In addition, the author takes Wuhu Fang Happy World as an example to study the impact of large-scale theme parks on urban tourism development and its temporal and spatial differentiation from the perspective of residents' perception [1]. The results show that local residents have a positive perception of the positive impact brought by the Fantail theme park; for the future development of the park, residents living farther from the theme park have a more positive attitude, and at the same time, compared to before the opening of the business, residents after the opening of the park for Fang Show more positive support attitude [2].

\section{Analysis of the Theme Park's Dependence on Regional Economy}

2.1 Lehua City's Dependence on the Level of Economic Development in Xixian New District.

The theme park has high input, high costs, large investment scale, high operation and maintenance costs, and demands for the strength of regional economic development. Without developed regional economic support, simply relying on the ability of the government or a certain enterprise cannot complete project development [3]. The theme park's success is inseparable from the background of regional economic development. Regional economically developed regions have relatively large-scale investment capabilities. In general, as the theme park for corporate behavior development, only large-scale investment capacity can be achieved in regions where the regional economy is relatively developed. This can be seen from the more successful cities developed in China theme parks [4].

The Bureau of Statistics of Xi'an issued the economic operation of Xi'an in 2017. Xi'an's gross domestic product (GDP) totaled 746.985 billion yuan, which was calculated at comparable prices and grew by $7.7 \%$ year-on-year, which was higher than the national 0.8 percentage point. This is also the first time that Xi'an's economic aggregate has reached 700 billion yuan, and it has once again achieved a place in the sub-provincial cities. In addition, Shaanxi Xixian New District was formally administered by Xi'an in early 2017. The statistics also included Xixian New District for the first time 
into the GDP statistics of Xi'an. Starting from 2018, Xi'an's ranking in the national GDP will continue to rise, and it will catch the smooth ride of the Guanzhong Plain City Group which has just been approved. The momentum of development in Xi'an will be even better in 2018[5].

\subsection{Lehua City's Dependence on Tourist Source Markets.}

Adjacent to the location assessment of Xixian New District, the source market can be divided into three levels according to the degree of access: first-class source market (1h car distance), second-level source market (3h car distance), and third-level source market (3h car distance above). For Xixian New District, Xianyang City and Xi'an City, there are a lot of tourists around it, including cities such as Yichang, causing relatively close travel costs. Followed by areas outside Shaanxi Province, including Hubei and Henan provinces, these distances, transportation, economy, people's desire for recreation and entertainment are generally chosen to go to Xi'an. Xi'an Tourist Market Analysis

In 2015, Xi'an received 136 million tourists at home and abroad, an increase of $13.3 \%$ year-on-year; total tourism revenue was 107.367 billion yuan, an increase of $13.0 \%$ year-on-year, equivalent to $18.5 \%$ of the city's GDP; and an increase of tourism value of 53.420 billion yuan. Accounted for $9.2 \%$ of the city's GDP. From the perspective of tourists, tourists from Shaanxi, Henan, Zhejiang, Shanxi, and Beijing accounted for the top five in the market and accounted for $38.4 \%$ of all tourists, which was lower than the 4.6 percentage points in the previous year. Shaanxi accounted for $11.5 \%$ of the total, which was 5.9 percentage points lower than the previous year, and Henan accounted for $9.1 \%$, which was 0.2 percentage points lower than the previous year. The same ranking as in the previous year was a difference of 2.4 percentage points from the first Shaanxi. In addition to the above five provinces (cities), Guangdong, Jiangsu, Sichuan, Hebei, and Shandong rank among the top ten to top ten. Tibet remains the last place, accounting for $0.2 \%$ of the total number of surveys.

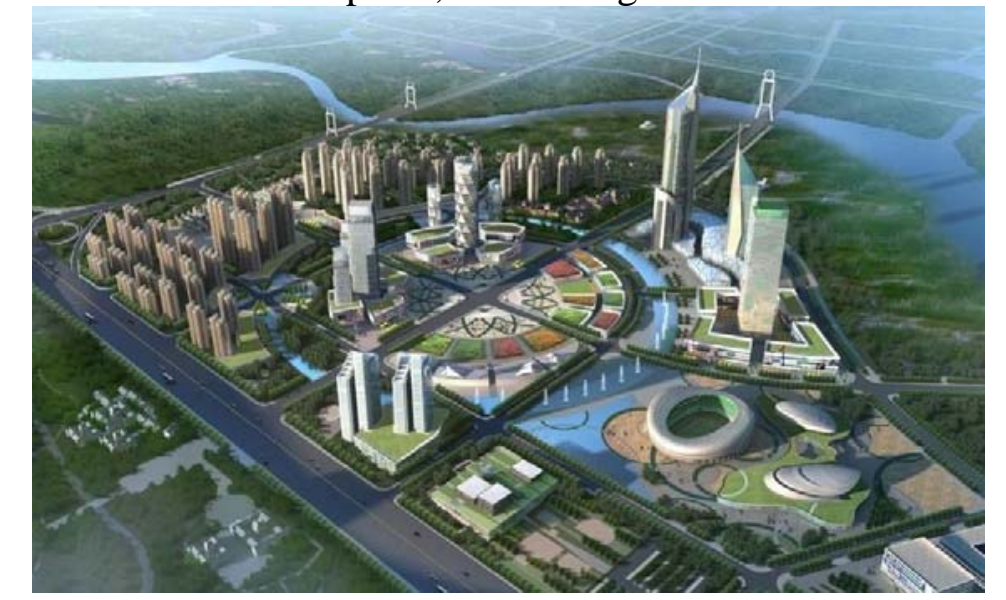

Fig 1. Xixian New District Development Advantages and Planning

\subsection{Population and Tourism Population.}

The theme park requires that it be located in large cities and mega cities with large floating population so as to ensure a good source market.

It is required to be located in large cities and mega cities with large floating population in order to ensure a good source market. According to research conducted by the Urban Land Institute of Washington, the first-class customer source market $(80 \mathrm{~km})$ of a large-scale theme park needs at least 2 million people, and the secondary source market (240 kilometers) has at least 3 million people. Analysis of Xi'an Market Sources and Analysis of Lehua City's Source Market

\subsection{Space Agglomeration Conditions of Tourist Attractions.}

A successful theme park has nothing to do with its size, and it is closely related to its core competitiveness. A theme park with core competitiveness should have the following characteristics: the project has high technology and artistic content; continuous innovation in hardware and software; entertainment projects are highly involved, enabling visitors to obtain new experiences, interactions, and satisfaction in entertainment the entertainment is placed in front of the viewing, so that visitors feel pleasure, thrills and stimuli in entertainment. Need to include the following aspects. 


\subsection{Regional Tourism Perception Image.}

The regional tourism image is a comprehensive concept that reflects the characteristics of the entire region as a tourism product and its overall quality level. In general, each region has a consistent tourist perception image for tourists. When talking about Xi'an, tourists will think of Terracotta Warriors and Horses.

Different regions have different tourism images and will have different impacts on the construction and development of local theme parks.

The regional tourism image mainly affects the decision-making behavior of tourists at the largeand medium-scale (Grade 3 and 3G source markets). In a tourist city like Xi'an, large and medium-scale tourists first choose national tourist attractions such as the Big Wild Goose Pagoda and the Terra Cotta Warriors. According to the survey, the proportion of foreign tourists in these areas is higher than that of the local people. Therefore, in areas where you have a very rich cultural landscape like Xi'an, and you have a relatively high level of tourism, visitors have a more fixed image of tourism perception. Tourists, especially the first-time visitors to Xi'an, are less attractive.

The construction of West Xixian New District is fast, the upper part of the city's image is stable, and the tourism resources are relatively poor. The tourism image is not as deep-rooted in the hearts of tourists as Xi'an, but it is in development and change.

From this, we can draw a preliminary conclusion that in regions where the popularity of small personalities is very strong, such as Xi'an, new theme parks cause a sensational effect and quickly become a symbol of the region's tourism image; at the same time, for large-scale tourists, special Visitors to the first trip are less attractive. In cities where the image of Liu's personality is still changing and not obvious, such as Xixian New District, the construction of a distinctive theme park can quickly become a new symbol of the regional tourism image, causing a sensational effect and appealing to tourists of all sizes.

\subsection{Study on Location Selection of Theme Parks.}

A large-scale theme park must be located in a market area that does not have strong competition. The first-level source market needs at least 10,000 people, the second class must have 10,000 people, and the third-level source market is also helpful, but due to the high cost of transportation in the third-class source market High, cannot be over-reliance on, expect the third-tier source market. The primary source market referred to here is within a mile or hour distance from the vehicle, and the secondary source market is within a mile or hour distance from the vehicle. Within this distance, tourists can return to and from the secondary market within a day and the floating population belongs. Third-level source market. The Institute's research also pointed out that the site selection of the theme park site should consider the following important factors besides or near the main trunk line of traffic, and secondary roads could be used as auxiliary or emergency entrances. With its wide line of sight, it can display landmarks to passing car drivers. There are enough water, electricity and sewage treatment facilities. Residents nearby do not object. With sufficient land, a large-scale theme park needs at least an acre, flat or slightly undulating terrain, and the ideal site is a rectangular one. Cities with high reputation are generally well-developed in economy; scenery and environment are good; the popularity of a city directly determines people's choices.

\subsection{Lehua City's Dependence on Infrastructure in Xixian New District.}

The first is the traffic conditions. The city where the theme park is located must have good access to the city's public transportation

Merciful. The theme park passenger flow has the characteristics of mass flow and high density gathering. Therefore, it is necessary to have a good traffic system. He can be divided into traffic outside of the country and traffic in the area. Outer traffic has enabled the region to attract mass standards (second and third-tier source markets), mainly in terms of airport throughput capacity, train and car transportation, and network and shipping capabilities. According to the law of differentiation and the degree of aggregation, resorts have a strong dependence on the mode of transportation. This dependence shows the dependence on the railway hub and highway trunk lines; it can be reached by subway to the north of Xi'an. Take Subway Line 2 and get off at City Sports Park. From the exit D to the north, 100 meters away from the Lok Wah Happy World parking lot, there is a private bus. 
The traffic conditions in the area have a great influence on the location and operation of theme parks. The convenient transportation is conducive to the construction and development of the theme park. The transportation is convenient enough to cope with the visitor's visit. It is very convenient for tourists to connect the RV-Routeing Airport Railway. This is very important for setting up a large-scale theme park.

If the traffic is not smooth, it will bring a lot of business problems. The toll station is plagued by traffic restrictions. If you follow the requirements of high speed, smooth flow, large capacity, zero transfer, it is actually very difficult to do. Traffic problems cannot solve the original functions of Shide theme park. For the vast majority of Xi'an tourists, the one-way journey takes about one hour. If the traffic problems during the day can be coped with, then after the large-scale night events, the traffic problem of tens of thousands of tourists leaving the park is even more serious.

Second, the regional water supply capacity, power supply capacity, and communications capabilities are also very secure. They are an indispensable external condition for the construction of theme parks. If there are problems in some parts, it will become an obstacle to the construction of theme parks.

Traffic accessibility, Lehua City's site selection, suburbs, small land restrictions, wide area and relatively low prices, reduced park construction costs, main roads, saving road investment, transportation capacity, good visibility, can be observed Places to set tourist attractions signs, strengthen the tourism image.

\subsection{Lehua City's Dependence on Macro Industrial Decision-Making in Xixian New District.}

From a macro perspective, the government's policy preferences are direct and crucial to the development of theme parks. Dynamic instability of government policies relatively speaking, the impact of the adjustment of government-related policies by the investors and operators of theme parks on the business parks of the theme parks is very significant. This impact will directly affect the management of the theme parks. Success or failure. The theme park is a kind of high-investment tourism project. The construction of the theme park hopes that the government department can help and promote it. The development of early theme parks is purely individual and corporate autonomous behavior. However, with the economic and social development, the investment behavior of individual entities is very difficult, and the government's supporting role is becoming increasingly prominent. Different from the development of ordinary tourism, the focus of national or regional government's policy support for theme parks is not the tilt of taxation and lending rates, but the refinancing and land price policies and infrastructure construction. Loose policy space and strong government support provide a solid foundation for zero debt operations at Paradise.

\section{The Theme Park's Driving Force for Regional Economy}

\subsection{Influence of Lehua City on tourism in Xixian New District.}

The establishment of Xixian New District is based on two considerations in Shaanxi Province: First, implement the national strategy - a major measure for the development of the western region, the Xixian Economic Zone, and the main functional areas of the country; and second, the need for Xi'an's urban development. After more than 30 years of rapid development during the reform and opening up, the main city of Xi'an has nearly 500 square kilometers. Under the background of the integration of Xi'an and Xianyang, it is possible to form a city "spreading cake" development. Therefore, in 2011, the Shaanxi Provincial Party Committee and the Provincial Government set up the Xixian New District between Xi'an and Xianyang built-up districts. They are dedicated to the construction of modern garden cities.

Lehua City International Happy Holiday Resort is the largest compound tourism Eco-city project in western China and China's first joyous theme Eco-resort. It has now opened and opened the biggest theme park in northwest China, Lehua Happy World and Asia Super-Hot Spring Water Theme Park $88^{\circ} \mathrm{C}$ hot spring park, has received more and more tourists, has become a popular tourist destination in Shaanxi and even the northwest region.It will become an oversized hot spring that combines indoor 
and outdoor water play, equipment experience, parent-child interaction, spa health, and can be opened 365 days a year. Water theme park. Xi'an Lehua City project will usher in a new explosion!

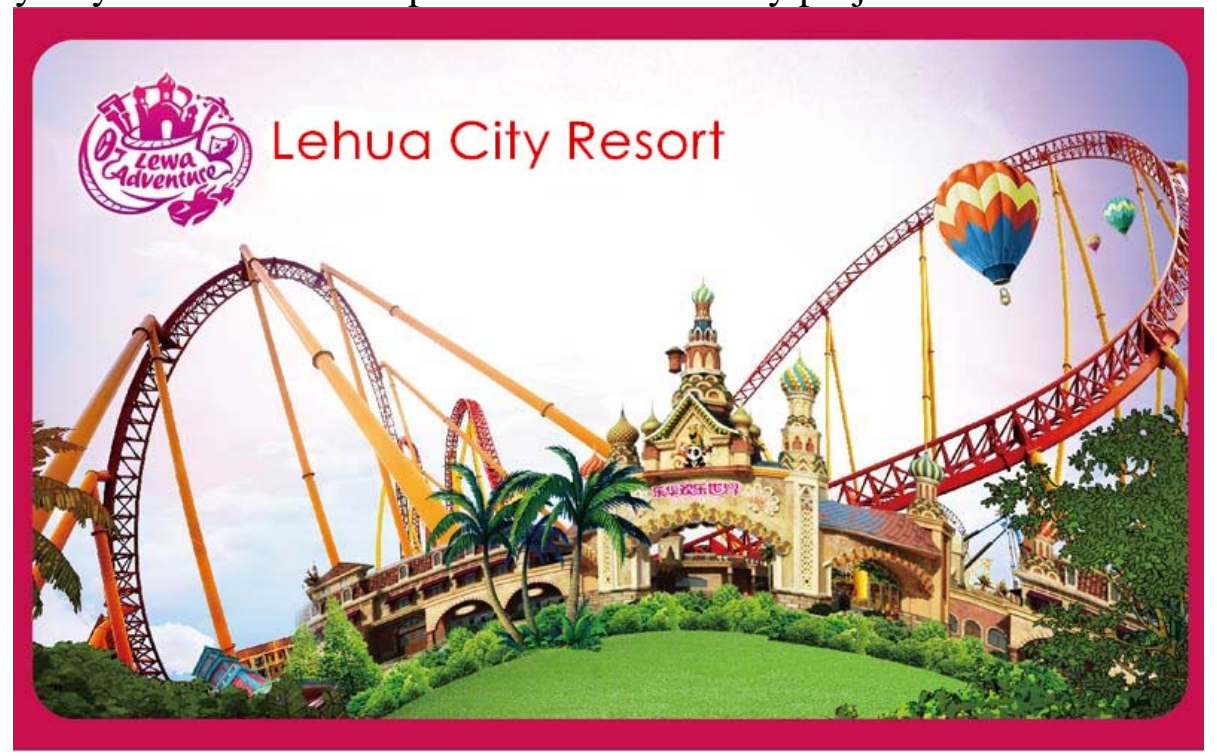

Fig 2. Lehua Happy World 4A Level Scenic Area

\subsection{Influence of Lehua City on Other Industries in Xixian New District.}

West Xi'an New District connects Xi'an and Xianyang to the ancient capitals. The rivers in the north lie in the mountains and the south in the Qianlong Mountains. The Guan he River runs through the three rivers of the Weise River, the Weise River, and the Weise River in the Gunship Plain. Yes. After the completion of the project, the amount of water to be diverted will reach 1.5 billion cubic meters per year. The reservoir will be located in Jading New City, Ishaan New District. Shaanxi has rich reserves of coal, oil, gas, salt, and soil energy resources. Guanzhong has developed agriculture and rich products.

\subsection{Lehua City's Overall Economic Drive in Xishan New District.}

Based on the industrial foundation and resource endowments of Xi'an and Xianyang, Xixian New District focuses on the development of six new industries: information technology, cultural tourism, high-end equipment manufacturing, new energy and new materials, health care, modern agriculture, and airport development. Planning and construction of the Jidong Science and Technology Resources Demonstration Park, Jidong Liucun Modern Industrial Park, Airport Comprehensive Bonded Zone, Airport Industrial Park, Daixi Information Industry Park, Daixi International Cultural Education Park, Zhoushan Emerging Industrial Park in Qin and Han, Five major industrial parks such as the Qin and Han Wuling Cultural Tourism Industrial Park, Luohe Logistics Business Park, and Luohe Geographic Information Industrial Park have formed the potential for complementary, dislocated and coordinated development of the five new cities.

\section{(1) Scale of Infrastructure Construction.}

Five roads and four bridges linking Xi'an Avenue and Xianyang Avenue in the main city of Xianyang have entered the rapid construction phase. Among them, the Qinhan Avenue Phase I, Handan Road New River Section and the Weihe River Crossing Bridge linking Xi'an and Xianyang were opened to traffic. At present, 400 kilometers of roads have been opened to traffic throughout the region, and the traffic skeleton has basically taken shape.

\section{(2) Synchronization of Public Services.}

The construction of the four medical university medical education and research Complex Park started construction. Shaanxi Business Expo Hall and Luohe Chongwen Tower Scenic Spot have been rated as national AAA-level scenic spots and have received more than 800,000 tourists. By the end of 2014, 40,800 sets of affordable housing had been completed in Xixian New District, with a total investment of 12.29 billion yuan. 
(3) The Ecological Environment Has Improved Significantly. 3.4 Economic Regional Transportation.

As an important trunk road in the overall planning of "Five Horizontal and Five Vertical" in Xixian New District, Zhengyang Avenue will greatly narrow the distance between Xi'an Main City and Luohe New City. It is expected that the Zhengyang Bridge will be officially opened to traffic in 2017. By then, it will only take 15 minutes to drive from the main city to the Lehua City project, effectively shortening the round-trip time and lengthening the time spent in the tourist park. The cancellation of the Nie Feng Toll Station, which has plagued the development of the new Luohe New City, has also been formally put on the agenda. At that time, there will be a grand view of Leroy, which will bring new opportunities to Lehwa City.

\subsection{Lehua Happy World 4th Grade National Scenic Area.}

In December 2016, the Shaanxi Provincial Tourism Bureau held 13 brand-new national 4A-level tourist attractions awarding ceremonies in Xi'an. The Lehua City and Lehua Happy World topped the list, and the first national Grade 4A in the Luohe New City area. Tourist area was born. This award is a great affirmation of the work of the Lok Wah Happy World Project and is a guarantee for the quality of the Lehua City Scenic Area. It is believed that Lehua City will continue to build on the 4A level scenic spot and build a foundation for visitors. Bring a better play experience.

\section{The Positive Interaction Between Theme Park and Regional Economy}

\subsection{The Influence of Regional Economic Power on Theme Parks.}

The theme park has different characteristics from general amusement parks and parks. The most obvious is its high investment and high cost. The theme park needs to reach a large scale in order to attract tourists, and the land area is often over hundreds of thousands of acres. The high price and high cost of one-time investment in high-tech equipment is huge. If the ratio of capital is not high, the debt pressure of the bank will inevitably be large. The theme park serves as a service enterprise, and the maintenance cost accounts for a high proportion, such as staff salary, equipment operation, and activity. Plant breeding, technical equipment updates and higher update rates.

\subsection{The Theme Park's Role in Promoting the Overall Economy of the Region.}

The theme park has a strong driving role in promoting the sales of tourism products. Due to the theme, entertainment and other characteristics of the theme park, the development and sales of tourist souvenirs is an indispensable part of its management. From an international perspective, the daily income of most successful theme parks is derived from tourist shopping and extra charges. For example, the British theme park revenues come from restaurants, souvenirs, and sales and other services. Establishing a new image of regional tourism with the development of tourism industry becoming more and more mature, the competition among tourism destinations has shifted from original resource competition, product competition and market competition to image competition. The successful experience of tourism developed countries in developing tourism is to shape the overall tourism image. The theme park is playing an increasingly important role in this competition.

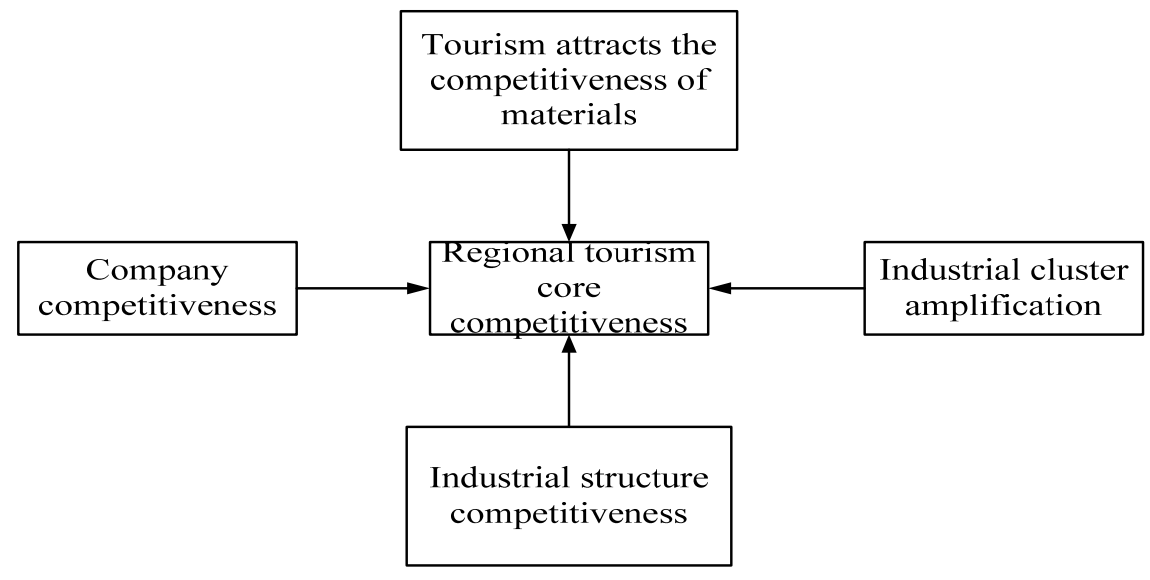

Fig 3. Regional Tourism Core Competence Model 


\section{Conclusion.}

The interactive relationship between the theme park and the regional economy is more and more proved by practice. This is also a proposition that is important for the theme park growth and regional economic development. Through the collection and analysis of a large number of actual cases, this article studies the theme park's dependence on regional economy and theme park's pulling power for regional economy. From the perspective of system theory, it demonstrates that the two are interdependent and promote mutual interaction. Effect. On this basis, the article further proposes how to use the intrinsic relationship between the two to promote their coordinated development. The growth pole theory and spot axis theory in regional economy have important theoretical guidance for the study of the theme parks' role in the region. The theme park can be regarded as the growth pole in the regional economy, which can produce polarization effect and diffusion effect, and drive the regional economic growth. At the same time, as the growth point of the regional economy, theme parks can generate radiation effects from the surrounding area, from "point-axis" to "point-axis-accumulation area."

\section{Acknowledgements}

This is the 2017 Shaanxi Provincial Department of Education Special Scientific Research Project "Study on the Interactive Relationship between the Theme Park and the Regional Economy: A Case Study of the Economic Interaction between Lehua City Resort and Xixian New District” (Project No. 17JK0970).

\section{References}

[1]. Li Rudi, et al. Chiung Xiong's theme park and the interaction between the development of the city's development Open Herald, Vol. 6 (2009) No.24, p.123-129.

[2]. Wang Xiaobo, Yu Xinxiang, et al. Dai Fading Chinese National Park in Beijing-An Architectural Creation Practice Based on Life and Originality, Vol. 3 (2012) No.35, p.331-339.

[3]. Zhu Yon Gwen, et al. Dong Gandhi tourism theme park management principles and practices "Guangdong Tourism Press, Vol. 5 (2011) No.27, p.128-132.

[4]. Yu Jingo, et al. Quantitative Study on the Law of Tourism Source Distribution of Tourism in Shenzhen Overseas Chinese Town Economic Geography, Vol. 1 (2015) No.19, p.82-86.

[5]. Liu Zhen in, et al. FU Jun's Research on the Construction and Development of Domestic Theme Parks Master Dissertation South China University of Technology, Vol. 8 (2016) No.21, p.371-376. 